Article

\title{
Carbonate-Catalyzed Room-Temperature Selective Reduction of Biomass-Derived 5-Hydroxymethylfurfural into 2,5-Bis(hydroxymethyl)furan
}

\author{
Jingxuan Long, Wenfeng Zhao, Yufei $\mathrm{Xu}, \mathrm{Hu} \mathrm{Li} * \mathbb{C}$ and Song Yang *(D) \\ State Key Laboratory Breeding Base of Green Pesticide \& Agricultural Bioengineering, \\ Key Laboratory of Green Pesticide \& Agricultural Bioengineering, Ministry of Education, \\ State-Local Joint Laboratory for Comprehensive Utilization of Biomass, Center for R\&D of Fine Chemicals, \\ Guizhou University, Guiyang 550025, China; gs.jxlong17@gzu.edu.cn (J.L.); fci.wfzhao18@gzu.edu.cn (W.Z.); \\ gs.yfxu17@gzu.edu.cn (Y.X.) \\ * Correspondence: hli13@gzu.edu.cn (H.L.); jhzx.msm@gmail.com (S.Y.); Tel.: +86-(851)-8829-2171 (H.L. \& S.Y.)
}

Received: 7 November 2018; Accepted: 4 December 2018; Published: 7 December 2018

\begin{abstract}
Catalytic reduction of 5-hydroxymethylfurfural (HMF), deemed as one of the key bio-based platform compounds, is a very promising pathway for the upgrading of biomass to biofuels and value-added chemicals. Conventional hydrogenation of HMF is mainly conducted over precious metal catalysts with high-pressure hydrogen. Here, a highly active, sustainable, and facile catalytic system composed of $\mathrm{K}_{2} \mathrm{CO}_{3}, \mathrm{Ph}_{2} \mathrm{SiH}_{2}$, and bio-based solvent 2-methyltetrahydrofuran (MTHF) was developed to be efficient for the reduction of HMF. At a low temperature of $25^{\circ} \mathrm{C}, \mathrm{HMF}$ could be completely converted to 2,5-bis(hydroxymethyl)furan (BHMF) in a good yield of $94 \%$ after $2 \mathrm{~h}$. Moreover, a plausible reaction mechanism was speculated, where siloxane in situ formed via hydrosilylation was found to be the key species responsible for the high reactivity.
\end{abstract}

Keywords: biomass conversion; biofuels; hydrogenation; green chemistry; sustainable catalysis

\section{Introduction}

As the depletion of traditional energy resources such as coal and petroleum continues, the efficient synthesis of fuels and value-added molecules from biomass is becoming both urgent and essential [1-6]. Among the biomass derivatives, 5-hydroxymethylfurfural (HMF), which can be obtained from sugars (e.g., fructose [7-10] and glucose [11-13]) via dehydration, is hailed as a key platform molecule for producing a variety of valuable products, see Figure $1[14,15]$. For example, catalytic oxidation of HMF can be converted to 2,5-diformylfuran (DFF), 2,5-furandicarboxylic acid (FDCA), 2-formyl-5-furancarboxylic acid (FFCA), and 5-hydroxymethyl-2-furancarboxylic acid (HMFCA) [14-17]. On the other hand, HMF can be hydrogenated to 2,5-bis(hydroxymethyl)- furan (BHMF), 1,6-hexanediol, 5-methylfurfural (MF), 2,5-dimethylfuran (DMF), 2,5-dimethoxytetrahydrofuran (DMTHF), and 2,5-dihydroxymethyl-tetrahydrofuran (DHMTHF) using various metals (e.g., $\mathrm{Pt}, \mathrm{Ru}, \mathrm{Pd}$, $\mathrm{Cu}, \mathrm{Zr}$ ) on different supports (e.g., $\mathrm{C}, \mathrm{SiO}_{2}, \mathrm{Co}_{3} \mathrm{O}_{4}$ ) [17-22]. As one of promising bio-based downstream products, $\mathrm{BHMF}$ can be applied in the preparation of various functional materials (e.g., polymers, resins, crown ethers, and artificial fibers), and used as versatile scaffolds in the preparation of medicines and relevant bioactive compounds [23]. 


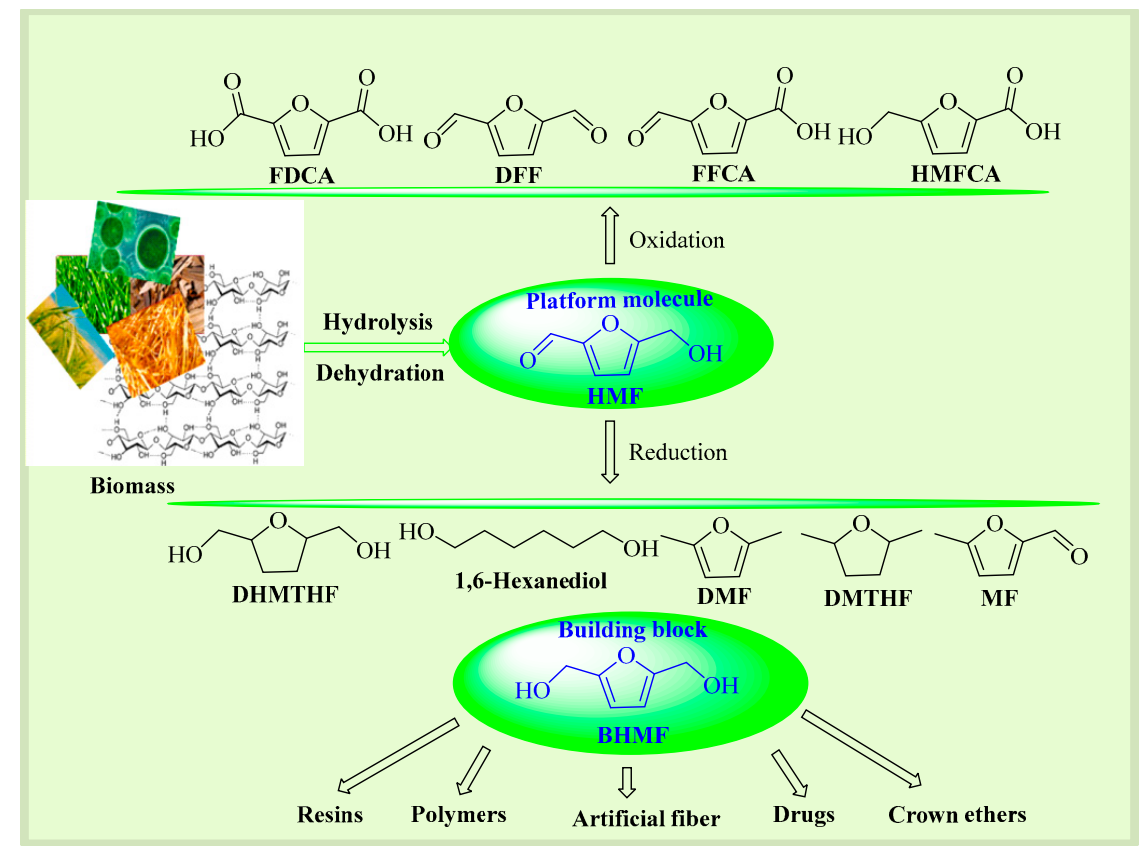

Figure 1. Schematic illustration for upgrading bio-based HMF to value-added products. (HMF: 5-hydroxymethylfurfural, BHMF: 2,5-bis(hydroxymethyl)-furan, FDCA: 2,5-furandicarboxylic acid, DFF: 2,5-diformylfuran, FFCA: 2-formyl-5-furancarboxylic acid, DMF: 2,5-dimethylfuran, HMFCA: 5-hydroxymethyl-2-furancarboxylic acid, DHMTHF: 2,5-dihydroxymethyl-tetrahydrofuran, DMTHF: 2,5-dimethoxytetrahydrofuran, MF: 5-methylfurfural).

In most cases, the efficient catalytic hydrogenation of HMF into BHMF mainly occurs over precious metals (e.g., $\mathrm{Ru}, \mathrm{Pd}$ ) [20,24], or transition metals (e.g., $\mathrm{Cu}$ ) [25-28] under a relatively high pressure of $\mathrm{H}_{2}(1-10 \mathrm{MPa})$, see Table 1 . The employed metallic catalysts are typically expensive, with relatively harsh reaction conditions [20,25]. Likewise, transfer hydrogenation using alcohol (e.g., ethanol, 2-propanol) or formic acid as the liquid hydrogen source has also attracted much attention from many researchers [21,25,29-32]. However, the use of formic acid may lead to the corrosion of the equipment and metal leaching, while the alcohol can further react with BHMF by etherification to reduce its selectivity [33]. Thereby, it is still essential to explore cheap and green alternative catalytic systems for the reduction of HMF to BHMF in high efficiencies.

Table 1. Activity comparison with previously reported results of HMF-to-BHMF hydrogenation.

\begin{tabular}{|c|c|c|c|c|c|c|c|}
\hline Entry & Catalyst & $\begin{array}{c}\text { Temperature } \\
\left({ }^{\circ} \mathrm{C}\right)\end{array}$ & $\begin{array}{l}\text { Time } \\
\text { (h) }\end{array}$ & $\begin{array}{l}\text { Mole/Pressure } \\
\text { of H-Donor }\end{array}$ & $\begin{array}{c}\text { Yield } \\
(\%)\end{array}$ & $\begin{array}{c}\text { Conversion } \\
(\%)\end{array}$ & Reference \\
\hline 1 & $\mathrm{Pd} / \mathrm{C}$ & 80 & 20 & $10 \mathrm{MPa} \mathrm{H}_{2}$ & 82 & 97 & [19] \\
\hline 2 & $\mathrm{Ru} / \mathrm{CeO}_{x}$ & 130 & 2 & $2.7 \mathrm{MPa} \mathrm{H}$ & 81 & 100 & [23] \\
\hline 3 & $\mathrm{Ru}-\mathrm{Mg}-\mathrm{Zr}$ & 130 & 2 & $2.72 \mathrm{MPa} \mathrm{H}_{2}$ & 94 & & [23] \\
\hline 4 & $\mathrm{Cu} / \mathrm{C}$ & 180 & 8 & $5 \mathrm{MPa} \mathrm{H}_{2}$ & 53.3 & 70 & [24] \\
\hline 5 & $\mathrm{Ru} / \mathrm{CoNi}$-LDO & 180 & 4 & $1 \mathrm{MPa} \mathrm{H}_{2}$ & 49.9 & 100 & [27] \\
\hline 6 & $\mathrm{Cu}(50)-\mathrm{SiO}_{2}$ & 100 & 4 & $1.5 \mathrm{MPa} \mathrm{H}_{2}$ & 93 & 95 & [28] \\
\hline 7 & $\mathrm{ZrO}(\mathrm{OH})_{2}$ & 150 & 2.5 & ethanol & 83.7 & 94.1 & [29] \\
\hline 8 & $\mathrm{ZrBa}(3)-\mathrm{SBA}$ & 150 & 2.5 & isopropanol & 55.4 & 58.8 & [30] \\
\hline 9 & $\mathrm{Cu} / \mathrm{AlO}_{x}$ & 220 & $\mathrm{CF}^{\mathrm{a}}$ & 1,4-butanediol & 93 & 94 & [25] \\
\hline 10 & $\mathrm{Ru} / \mathrm{Co}_{3} \mathrm{O}_{4}$ & 190 & 6 & isopropanol & 82.8 & 100 & [20] \\
\hline 11 & $\mathrm{Cm}^{*} \mathrm{Ru}(\mathrm{HTsDPEN})$ & 40 & 2 & formic acid & 99 & 100 & [31] \\
\hline 12 & $\mathrm{Pd} / \mathrm{C}$ & 70 & 4 & formic acid & 94 & - & [32] \\
\hline 13 & $\mathrm{~K}_{2} \mathrm{CO}_{3}$ & 25 & 2 & $\mathrm{Ph}_{2} \mathrm{SiH}_{2}$ & 94 & 100 & This work \\
\hline
\end{tabular}

Hydrosilylation of carbonyl compounds to siloxanes shows great potential in the selective synthesis of alcohols [34,35]. This type of conversion process is very attractive because the used silanes are a water- and air-stable hydrogen source, which is able to be stimulated by metal-containing 
catalysts under mild conditions [22,36-40]. In addition, the strongly basic solvent used was proposed to facilitate its coordination with the catalytically active species (e.g., carbonate) [41], which is favorable for the reaction with silane to release hydride. In this regard, 2-methyltetrahydrofuran (MTHF) with relatively strong Lewis basicity [42], which is derivable from renewable lignocellulosic biomass [43], may have the superior capability to promote the hydrogenation of carboxides using hydrosilanes and is also preferable to protect the environment [44-46]. These features make MTHF a very attractive solvent for organic reactions, potentially in the efficient synthesis of BHMF from HMF.

In the present work, potassium carbonate, an abundant, readily available, and cost-effective salt, is developed to be highly efficient for chemoselective hydrogenation of HMF into BHMF at room temperature employing $\mathrm{Ph}_{2} \mathrm{SiH}_{2}$ and MTHF as the hydrogen source and solvent, respectively. The effects of different experimental parameters, including various catalysts, solvent type, reaction time, catalyst dosage, and hydrosilane amount on the reaction activity were studied. In addition, the reaction mechanism was also elucidated.

\section{Results and Discussions}

\subsection{Effect of Different Catalysts}

The reactivity of various catalysts on the synthesis of BHMF from HMF was first studied using $\mathrm{Ph}_{2} \mathrm{SiH}_{2}$ as an H-donor at room temperature in MTHF. Without a catalyst, no reaction took place, see Table 2, entry 1 , indicating that the reaction was chemically stable at examined conditions (room temperature for $2 \mathrm{~h}$ ). The presence of $\mathrm{K}_{2} \mathrm{CO}_{3}$ was found to be highly efficient for the hydrogenation of HMF (100\% conversion) under identical conditions, giving BHMF in 70.1\% yield, see Table 2, entry 2 . Gratifyingly, after post-treatment with methanol, a much higher BHMF yield (94.2\%) was obtained, see Table 2, entry 3 . The relatively lower selectivity toward BHMF without methanol treatment was due to the formation of the siloxane intermediate, as identified by LC-MS, see Figure S1, while the addition of methanol could facilitate the breakage of the siloxane bond to give BHMF in high selectivity. By comparison, almost no reaction occurred when employing $\mathrm{Li}_{2} \mathrm{CO}_{3}, \mathrm{Na}_{2} \mathrm{CO}_{3}, \mathrm{KCl}, \mathrm{CaCO}_{3}$, or $\mathrm{SrCO}_{3}$ as a catalyst (entries 6-10), while $\mathrm{KHCO}_{3}$ and $\mathrm{CH}_{3} \mathrm{COOK}$ gave no more than $40 \%$ BHMF yield at an HMF conversion of around $50 \%$ (entries 4 and 5). These results indicated that both cations and anions played a crucial role in the reaction. With the increase of the cation radius, the salt ionic property increased, thus showing enhanced solubility [47]. Among the alkali/alkaline earth metals, $\mathrm{K}^{+}$(with a relatively larger ionic radius) allows the paired carbonate to be more freely available to contact the hydrosilane and substrate. Apart from the cation, the influence of the anion on the reaction is not negligible, mainly with respect to its basicity that has a positive correlation with nucleophilicity. In this regard, carbonate with good accessibility and relatively high nucleophilicity is more prone to attack and activate the silane, $\mathrm{Ph}_{2} \mathrm{SiH}_{2}$, to release hydride [47]. In view of the superior BHMF yield, $\mathrm{K}_{2} \mathrm{CO}_{3}$ was chosen as the optimized catalyst for the reduction process.

Table 2. The results for reduction of HMF to BHMF over difference catalysts.

\begin{tabular}{cccc}
\hline Entry & Catalyst & Yield (\%) & Conversion (\%) \\
\hline 1 & none & 0 & 0 \\
2 & $\mathrm{~K}_{2} \mathrm{CO}_{3}$ & 70.1 & 100 \\
$3^{\mathrm{a}}$ & $\mathrm{K}_{2} \mathrm{CO}_{3}$ & 94.2 & 100 \\
4 & $\mathrm{KHCO}_{3}$ & 40.0 & 53.1 \\
5 & $\mathrm{CH}_{3} \mathrm{COOK}_{2}$ & 35.0 & 50.2 \\
6 & $\mathrm{Li}_{2} \mathrm{CO}_{3}$ & 0 & $<1$ \\
7 & $\mathrm{Na}_{2} \mathrm{CO}_{3}$ & 0 & $<1$ \\
8 & $\mathrm{KCl}_{9}$ & 0 & 0 \\
9 & $\mathrm{CaCO}_{3}$ & 0 & 0 \\
10 & $\mathrm{SrCO}_{3}$ & 0 & $<1$ \\
\hline
\end{tabular}

Reaction conditions: HMF $(0.5 \mathrm{mmol})$, catalyst $(0.1 \mathrm{mmol}), \mathrm{Ph}_{2} \mathrm{SiH}_{2}\left(1.4 \mathrm{mmol} \mathrm{H}^{-}\right), \mathrm{MTHF}(2 \mathrm{~mL}), 25^{\circ} \mathrm{C}$, and $2 \mathrm{~h}$. a After the reaction, $3 \mathrm{~mL}$ methanol was added into the resulting mixture, followed by stirring under ambient conditions for $30 \mathrm{~min}$. 


\subsection{Influence of Reaction Time}

In the assistance of the optimized catalyst, $\mathrm{K}_{2} \mathrm{CO}_{3}$, the influence of the reaction time on the hydrogenation of HMF to BHMF was studied. All experiments were conducted at $25{ }^{\circ} \mathrm{C}$ with the reaction time of $0.5-6 \mathrm{~h}$ and the results are displayed in Figure 2. Both the yield of BHMF and the conversion of HMF increased with prolonging the time-course from $0.5 \mathrm{~h}$ to $2 \mathrm{~h}$, demonstrating that a comparatively longer reaction time could promote the formation of BHMF. However, the BHMF selectivity decreased as the time was extended to $4 \mathrm{~h}$, possibly due to generating cross-linked siloxanes. These results obviously revealed that the hydrogenation of HMF to BHMF employing this facile and benign catalytic system was extremely selective and active, in comparison with other previous ones utilizing $\mathrm{H}_{2}$, alcohol, or formic acid as the hydrogen source, see Table 1 . Therefore, $2 \mathrm{~h}$ and $25^{\circ} \mathrm{C}$ were chosen to be the optimized reaction time and temperature, respectively, with $\mathrm{K}_{2} \mathrm{CO}_{3}$ as the catalyst for the subsequent study.

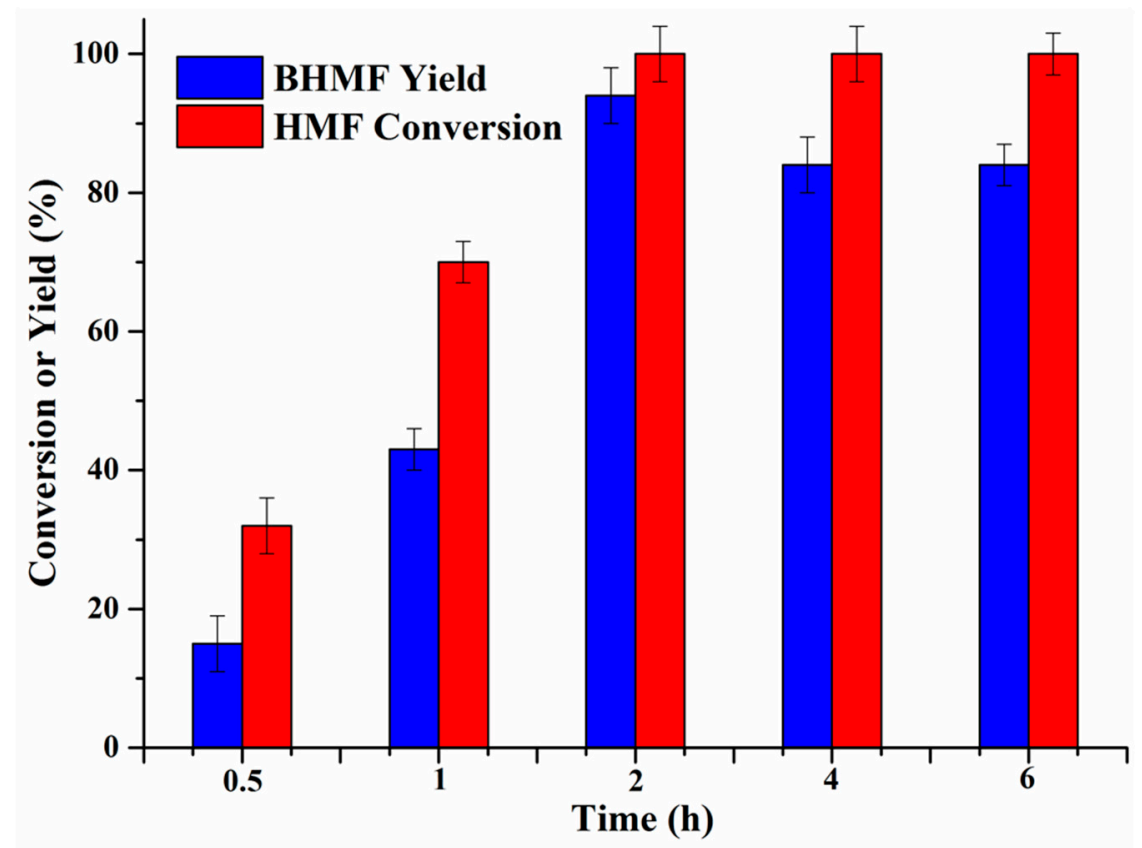

Figure 2. The effect of reaction time on the reduction of HMF into BHMF. (Reaction conditions: HMF (0.5 mmol), $\mathrm{K}_{2} \mathrm{CO}_{3}(0.1 \mathrm{mmol}), \mathrm{Ph}_{2} \mathrm{SiH}_{2}\left(1.4 \mathrm{mmol} \mathrm{H}{ }^{-}\right)$, MTHF $(2 \mathrm{~mL})$, and $25^{\circ} \mathrm{C}$; After the reaction, $3 \mathrm{~mL}$ methanol was added into the resulting mixture, followed by stirring under ambient conditions for $30 \mathrm{~min}$.)

\subsection{Influence of Various Solvents}

The effect of the used solvents in the reduction reaction was also investigated. MTHF, an aprotic solvent, with relatively high polarity, displayed high HMF conversion (100\%) and satisfactory BHMF yield (94\%), see Figure 3. In contrast, the solvents (e.g., DCM, 1,4-dioxane, $\mathrm{CH}_{3} \mathrm{CN}$, THF, and GVL) with relatively low polarity exhibited inferior performance, affording BHMF in yields of $20.1 \%, 25.2 \%$, $60.0 \%, 67.1 \%$, and $70 \%$, respectively. A solvent with moderate polarity could affect the solvent-reactant interactions $[48,49]$, where the increased interaction of HMF and solvent might promote the formation of BHMF. On the other hand, the solubility of $\mathrm{Ph}_{2} \mathrm{SiH}_{2}$ can also be enhanced by compatible polarity of the solvent, thereby facilitating the interaction of $\mathrm{Ph}_{2} \mathrm{SiH}_{2}$ with the catalyst to release $\mathrm{H}^{-}$. Overall, the appropriate interaction between the solvent, hydrosilane, and catalyst can facilitate the release of hydride to attack HMF, thus giving BHMF in a good yield. 


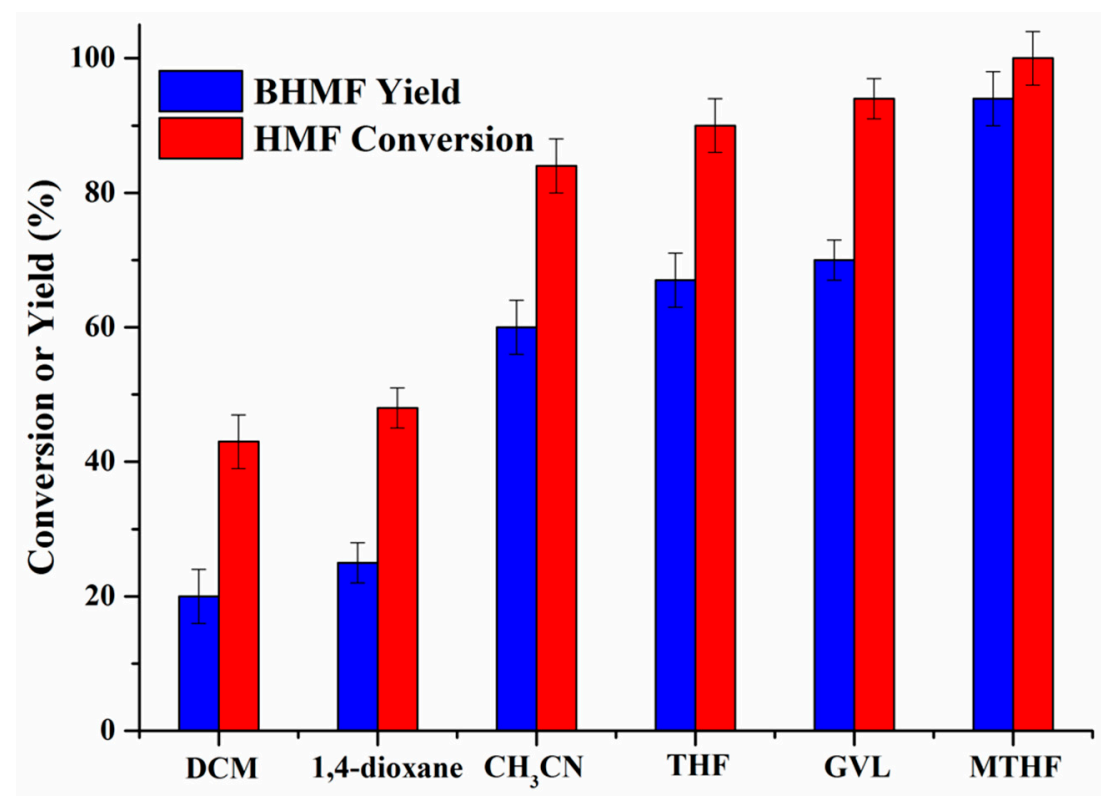

Figure 3. Effect of solvent type on reduction of HMF into BHMF. (Reaction conditions: HMF (0.5 mmol), $\mathrm{K}_{2} \mathrm{CO}_{3}(0.1 \mathrm{mmol}), \mathrm{Ph}_{2} \mathrm{SiH}_{2}\left(1.4 \mathrm{mmol} \mathrm{H}^{-}\right)$, solvent $(2 \mathrm{~mL}), 25^{\circ} \mathrm{C}$, and $2 \mathrm{~h}$; After the reaction, $3 \mathrm{~mL}$ methanol was added into the resulting mixture, followed by stirring under ambient conditions for $30 \mathrm{~min}$.)

\subsection{Influence of Different Hydrosilanes}

The influence of various hydrosilanes on the catalytic reduction of HMF into BHMF was studied by using $\mathrm{K}_{2} \mathrm{CO}_{3}$ as the catalyst, see Table $\mathrm{S} 1$. Among the employed simple silanes, phenylsilane $\left(\mathrm{PhSiH}_{3}\right)$ and diphenylsilane $\left(\mathrm{Ph}_{2} \mathrm{SiH}_{2}\right)$, see Table S1, entries 5 and 6, revealed relatively higher yields of BHMF, which might be due to their superior hydride-donating capability [50]. Although the conversion of HMF reached $100 \%$ with PMHS as an H-donor, the obtained BMHF yield was relatively low (66.0\%). The possible reason is that PMHS might react with products and substrates, forming insoluble PMHS-derived resin in a relatively large molecular weight under alkaline conditions, see Figure S2B. Even after adding methanol, the formed solid was not completely dissolved, see Figure S2C, indicating the relatively stable resin structure. It can be speculated that some of the formed silicon-oxygen bonds could not be cleaved during the post-treatment with methanol, thus impeding the formation of BHMF with a high selectivity. In view of the superior BHMF yield, $\mathrm{Ph}_{2} \mathrm{SiH}_{2}$ as a comparatively cheap hydrogen source was screened out for further optimization of HMF hydrogenation.

\subsection{Influence of $\mathrm{Ph}_{2} \mathrm{SiH}_{2}$ Dosage}

The $\mathrm{Ph}_{2} \mathrm{SiH}_{2}$ dosage was found to have a significant effect on BHMF synthesis, as shown in Figure 4. As the dosage of $\mathrm{Ph}_{2} \mathrm{SiH}_{2}$ rose from 0.05 to $0.7 \mathrm{mmol}$, the yield of $\mathrm{BHMF}$ was observed to increase from 20.0 to $94.2 \%$, accordingly. Nevertheless, when the PMHS dosage was more than $0.7 \mathrm{mmol}$, the BHMF yield was decreased despite constant HMF conversion. The decline in the yield of BHMF was most likely caused by the reaction of excessive $\mathrm{Ph}_{2} \mathrm{SiH}_{2}$ with potassium carbonate and BHMF to form cross-linked siloxanes that are too stable to hydrolyze even proceeding post-treatment with methanol. In a word, the use of $0.7 \mathrm{mmol} \mathrm{Ph}_{2} \mathrm{SiH}_{2}$ was favorable to attain the highest BMHF yield at $25^{\circ} \mathrm{C}$ for $2 \mathrm{~h}$ in MTHF. 


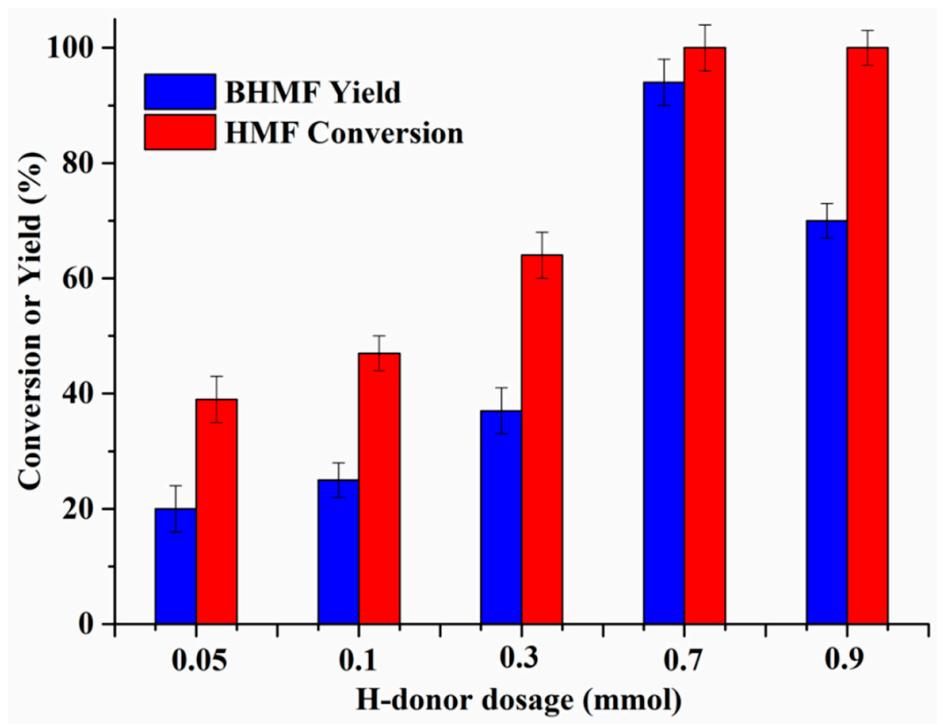

Figure 4. Effect of $\mathrm{H}^{-}$dosage of $\mathrm{Ph}_{2} \mathrm{SiH}_{2}$ on the reduction of HMF into BHMF. (Reaction conditions: $\operatorname{HMF}(0.5 \mathrm{mmol}), \mathrm{K}_{2} \mathrm{CO}_{3}(0.1 \mathrm{mmol}), \operatorname{MTHF}(2 \mathrm{~mL}), 25^{\circ} \mathrm{C}$, and $2 \mathrm{~h}$; After the reaction, $3 \mathrm{~mL}$ methanol was added into the resulting mixture, followed by stirring under ambient conditions for $30 \mathrm{~min}$.)

\subsection{Influence of Catalyst Dosage}

The effect of the $\mathrm{K}_{2} \mathrm{CO}_{3}$ dosage on the production of BHMF from HMF under the optimal conditions was further investigated at $25{ }^{\circ} \mathrm{C}$ over a period of $2 \mathrm{~h}$, see Figure 5 . When the $\mathrm{K}_{2} \mathrm{CO}_{3}$ dosage increased from 0 to $0.1 \mathrm{mmol}$, the conversion of the HMF and BHMF yield rose to $100 \%$ and $94.2 \%$, respectively. However, as the catalyst dosage was beyond $0.1 \mathrm{mmol}$, the yield of BHMF displayed a remarkable reduction, which could be attributed to BHMF adsorption onto the surface of solid $\mathrm{K}_{2} \mathrm{CO}_{3}$, thus inhibiting the alcoholysis of the siloxane intermediate to release the product BHMF [32]. In addition, the fast depletion of $\mathrm{Ph}_{2} \mathrm{SiH}_{2}$ was most likely to occur by forming pentavalent silicate species $\left(\left(\mathrm{Ph}_{2} \mathrm{SiH}_{2}\right)-\mathrm{CO}_{3}\right)$ with carbonate [51]. Although the pentavalent silicate species were active for hydrogenating carboxides [52], serious polymerization was prone to happen due to utilizing superfluous $\mathrm{K}_{2} \mathrm{CO}_{3}$ (e.g., $0.25 \mathrm{mmol}$ ), hence possibly decreasing the catalyst activity.

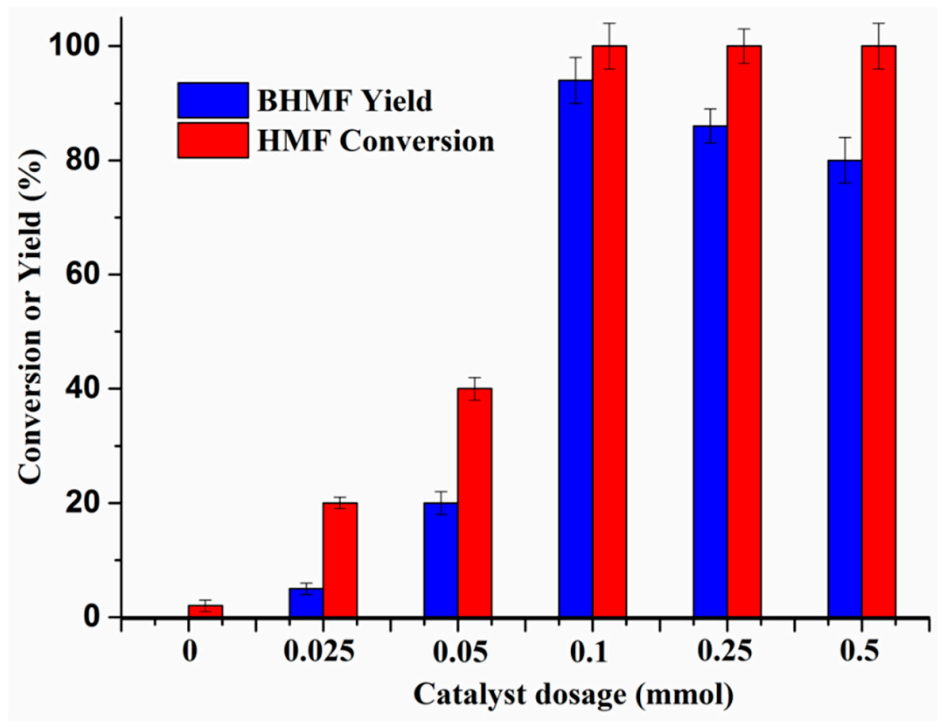

Figure 5. Influence of $\mathrm{K}_{2} \mathrm{CO}_{3}$ dosage on synthesis of BHMF from HMF. (Reaction conditions: HMF (0.5 mmol), $\mathrm{Ph}_{2} \mathrm{SiH}_{2}\left(1.4 \mathrm{mmol} \mathrm{H}^{-}\right)$, MTHF $(2 \mathrm{~mL}), 25^{\circ} \mathrm{C}$, and $2 \mathrm{~h}$; After the reaction, $3 \mathrm{~mL}$ methanol was added into the resulting mixture, followed by stirring under ambient conditions for $30 \mathrm{~min}$.) 


\subsection{Reaction Mechanism for HMF-to-BHMF Hydrogenation}

To explicitly interpret the reaction mechanism for hydrogenating HMF to BHMF, ex situ ${ }^{1} \mathrm{H}$ NMR spectra were recorded at $25{ }^{\circ} \mathrm{C}$ in the time course of $0.5-2 \mathrm{~h}$, see Figure 6 . The aldehydic proton 1a of HMF gradually disappeared, while the protons of hydroxyl $2 \mathrm{c}$ and methine of the furan ring $\mathbf{2 a}$ of BHMF were also detected and significantly enlarged by further extending the reaction duration. The mechanism for the hydrogenation of aldehydes or ketones catalyzed by $\mathrm{K}_{2} \mathrm{CO}_{3}$ was thus proposed to be very similar to the reduction process of amides [53], where $\mathrm{Ph}_{2} \mathrm{SiH}_{2}$ might act as an $\mathrm{H}$-donor to promote the reduction of HMF to BHMF, as demonstrated by in situ NMR in our previous study [39]. The possible reaction mechanism of the hydrogenation of HMF to BHMF is shown in Scheme 1. Initially, the interaction of a Lewis base (carbonate) and $\mathrm{Ph}_{2} \mathrm{SiH}_{2}$ forms a high-valency silicate species, which is a nucleophile in nature [54] and can activate the aldehyde group by hydride transfer to afford the siloxane intermediate, followed by hydrolysis to give BHMF. This catalytic system is simple to operate and does not produce observable byproducts during the reduction process, compared with other previous reaction systems [26,27].

To make our process more promising for real application, relatively stable sugar like fructose has been used as the starting material instead of unstable HMF. It was found that a moderate yield of BHMF (66\%) could be obtained via a one-pot two-step reaction process separately catalyzed by Amberlyst- 15 and $\mathrm{K}_{2} \mathrm{CO}_{3}$. This sequential process makes the biomass derivative HMF a promising platform molecule for the production of value-added chemicals.

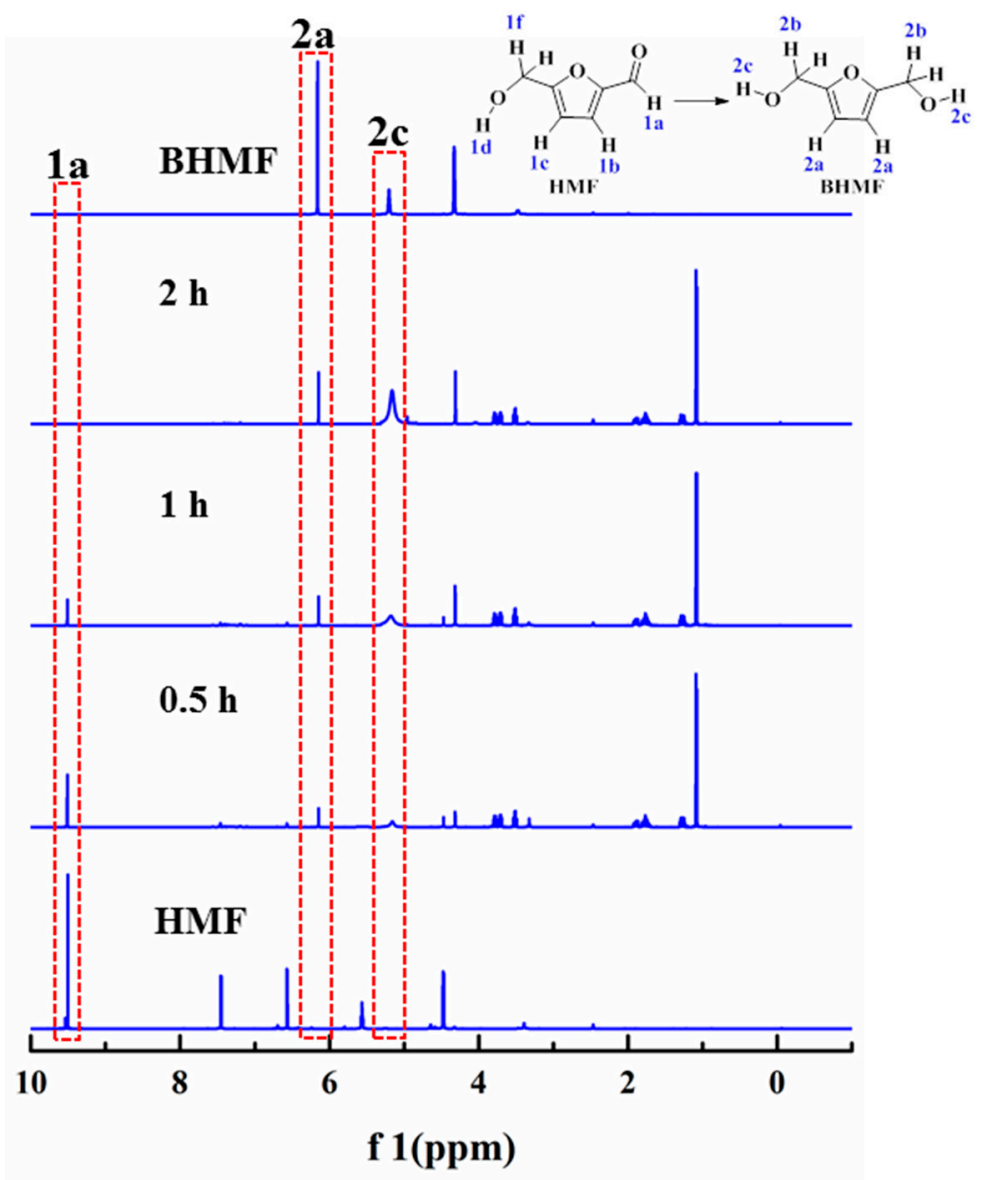

Figure 6. Ex situ ${ }^{1} \mathrm{H}$ NMR spectra of hydrogenating $\mathrm{HMF}$ to $\mathrm{BHMF}$ at $25{ }^{\circ} \mathrm{C}$ in $0.5-2 \mathrm{~h}$. (Reaction conditions: $\mathrm{HMF}$ (0.5 mmol), $\mathrm{Ph}_{2} \mathrm{SiH}_{2}\left(1.4 \mathrm{mmol} \mathrm{H}{ }^{-}\right), \mathrm{K}_{2} \mathrm{CO}_{3}(0.1 \mathrm{mmol})$, and MTHF (2.0 mL); After the reaction proceeded for $2 \mathrm{~h}, 3 \mathrm{~mL} \mathrm{CD} \mathrm{OD}_{3}$ was added into the resulting mixture, followed by stirring under ambient conditions for $30 \mathrm{~min}$.) 


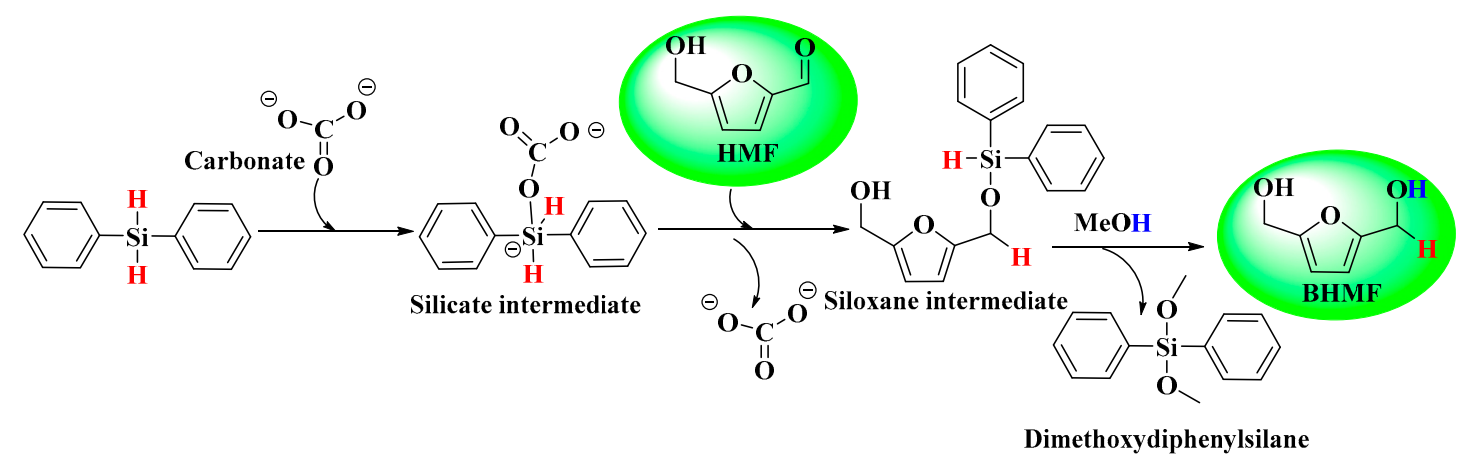

Scheme 1. Plausible reaction pathway for the HMF-to-BHMF reduction.

\section{Materials and Experiments}

\subsection{Materials}

5-hydroxymethylfurfural (HMF, 99\%), 2,5-bis(hydroxymethyl)furan (BHMF, 99\%), phenylsilane (97\%), polymethylhydrosiloxane (PMHS, 99\%), triethoxysilane (97\%), diphenylsilane (97\%), deuterated dimethyl sulfoxide (DMSO- $d_{6}, 99.8$ at.\% D), deuterated methanol ( $\mathrm{CD}_{3} \mathrm{OD}, 99.8$ at.\% D), 1,4-dioxane (99\%), potassium carbonate $\left(\mathrm{K}_{2} \mathrm{CO}_{3}, 99 \%\right)$, gamma-valerolactone (GVL, 99\%), naphthalene (99\%), methanol (99\%), triethylsilane (99\%), trimethoxysilane (99\%), Amberlyst-15 (>99\%), fructose (>99\%), and 1,1,3,3-tetramethyldisiloxane (97\%) were bought from Innochem Technology Co., Ltd. (Beijing, China). Tetrahydrofuran (THF, 99\%) was bought from Shanghai TCI Develop. Co., Ltd. (Shanghai, China). Lithium carbonate $\left(\mathrm{Li}_{2} \mathrm{CO}_{3}, 99 \%\right)$ and sodium carbonate $\left(\mathrm{Na}_{2} \mathrm{CO}_{3}, 99 \%\right)$ were purchased from Aladdin Ind. Inc. (Shanghai, China). Potassium bicarbonate $\left(\mathrm{KHCO}_{3}, 99 \%\right)$, potassium chloride ( $\mathrm{KCl}, 98 \%$ ), acetonitrile (MeCN, 99\%), 2-methyltetrahydrofuran (MTHF, 99\%), and dichloromethane (DCM, 99\%) were bought from Sigma-Aldrich Co. LLC. (Shanghai, China). Other used chemicals were of analytical grade without further purification, unless stated otherwise.

\subsection{Procedures for Catalytic Reduction of HMF into BHMF}

The tested reactions were all conducted in Ace pressure tubes $(15 \mathrm{~mL})$. In a general reaction process, $0.5 \mathrm{mmol} \mathrm{HMF,} 0.1 \mathrm{mmol} \mathrm{K} 2 \mathrm{CO}_{3}, 2.0 \mathrm{~mL} \mathrm{MTHF}$, and $0.7 \mathrm{mmol} \mathrm{Ph}_{2} \mathrm{SiH}_{2}$ were added into the reactor and sealed. Afterwards, the tube was moved into an oil-bath under magnetic stirring at $400 \mathrm{rpm}$ for a certain period. The zero time was established when the reactor was placed in the bath $\left(25^{\circ} \mathrm{C}\right)$. Upon completion, methanol $(3 \mathrm{~mL})$ was added into the resulting mixture, followed by stirring under ambient conditions for $30 \mathrm{~min}$ to proceed alcoholysis of the siloxane intermediate. Then, the resulting reaction solution was filtered to remove solid particles, while the yield of BHMF was quantified by GC and the conversion of HMF was analyzed by HPLC. When fructose $(0.5 \mathrm{mmol})$ instead of $\mathrm{HMF}$ was used as the substrate, an additional reaction process catalyzed by Amberlyst- 15 (15 mg) at $120^{\circ} \mathrm{C}$ for $45 \mathrm{~min}$ was conducted prior to the reduction process under otherwise identical reaction conditions. All the reactions were repeated three times, and the obtained results were the average values of three individual experiments, with a standard deviation $(\sigma)$ of $0.5-4.2 \%$.

\subsection{Analytical Methods 1100 (Agilent Technologies) system}

HMF conversion was analyzed by HPLC (1100 series, Agilent Technologies Inc., CA, USA) equipped with a refractive index detector, an ultraviolet detector $(\lambda=284 \mathrm{~nm})$, and an Aminex HPX-87H column (Bio-Rad Laboratories, Hercules, CA, USA). The column temperature was set at $25^{\circ} \mathrm{C}$, and the mobile phase used was acetonitrile $/ 0.1 \mathrm{wt} . \%$ acetic acid aqueous solution $(30: 70, v / v)$ at a flow rate of $1.0 \mathrm{~mL} \mathrm{~min}^{-1}$ (HMF retention time: $3.7 \mathrm{~min}$ ). BHMF was quantitatively analyzed by an Agilent 7890B GC (Agilent Technologies Inc., Santa Clara, CA, USA) fitted with a flame ionization detector and an HP-5 column. Analysis conditions were optimized as $1 \mu \mathrm{L}$ injection volume, $0.7 \mathrm{~mL} / \mathrm{min}$ nitrogen 
carrier gas, $75: 1$ split ratio, with injector and detector temperatures of 240 and $280^{\circ} \mathrm{C}$, respectively; oven temperature programmed from $60^{\circ} \mathrm{C}$ (keeping for $1 \mathrm{~min}$ ) to $100{ }^{\circ} \mathrm{C}$ at a rate of $5{ }^{\circ} \mathrm{C} / \mathrm{min}$, then raised to $270{ }^{\circ} \mathrm{C}$ (keeping for $2 \mathrm{~min}$ ) at a rate of $10^{\circ} \mathrm{C} / \mathrm{min}$ (BHMF retention time: $14.7 \mathrm{~min}$ ). Naphthalene (10 $\mathrm{mg}$ ) was used as an internal standard. The products were quantified based on the standard curves of the corresponding commercial reagents $\left(R^{2} \geq 0.9997\right)$. In addition, liquid products were identified by GC-MS (6890N GC/5973 MS, Agilent Technologies Inc., CA, USA), while a siloxane intermediate was identified by liquid chromatography/mass spectrometry (LC-MS) (Ultimate 3000 LC/Q Exactive MS, Thermo Fisher Scientific, San Jose, CA, USA).

\subsection{Reaction Time-Course Study}

For the time-course study of the reaction with NMR, after the reaction had proceeded for a specific time $(0.5-2 \mathrm{~h}), 3 \mathrm{~mL}$ deuterated methanol was added into the reaction solution, followed by stirring under ambient conditions for $30 \mathrm{~min}$, and then $0.5 \mathrm{~mL}$ of the reaction solution was taken. ${ }^{1} \mathrm{H}$ NMR spectra of the reaction mixtures were performed using an NMR spectrometer (JEOL-ECX 500, JEOL, Tokyo, Japan).

\section{Conclusions}

In this work, a benign and efficient catalytic protocol was developed for selective hydrogenation of HMF into BHMF in good yields (ca. 94\%) at room temperature for $2 \mathrm{~h}$, using abundant, readily available, and cost-effective $\mathrm{K}_{2} \mathrm{CO}_{3}$ as the catalyst, eco-friendly $\mathrm{Ph}_{2} \mathrm{SiH}_{2}$ as the hydrogen source, and green and renewable MTHF as the solvent. The developed silane-mediated catalytic system was extremely active and selective, in comparison with previous reports that use noble or transition metals as a catalyst while $\mathrm{H}_{2}$, formic acid, or alcohol as the hydrogen source. The mechanistic study illustrated the reaction proceeded via the hydrosilylation process with a high-valency silicate species as the key hydride species formed by the activation of $\mathrm{Ph}_{2} \mathrm{SiH}_{2}$ with carbonate, which can greatly facilitate the hydride transfer toward the aldehyde group to afford the siloxane intermediate. Subsequently, BHMF is obtained by the in situ hydrolysis of the siloxane intermediate, which can be significantly promoted by post-treatment with methanol. Moreover, this catalytic system is simple to operate and produces fewer byproducts during the process, exhibiting great promise for biomass upgrading.

Supplementary Materials: The Supplementary Materials are available online at http:/ /www.mdpi.com/20734344/8/12/633/s1. Figure S1. LC-MS spectrum of the siloxane intermediate obtained in the hydrogenation of HMF to BHMF; Figure S2. Images of the $\mathrm{K}_{2} \mathrm{CO}_{3}$-catalyzed hydrogenation of HMF to BHMF using PMHS as H-donor; Figure S3. GC-MS spectrum of BMHF obtained from hydrogenation of HMF; Figure S4. GC-MS spectrum of dimethoxydiphenylsilane obtained from the interaction of $\mathrm{Ph}_{2} \mathrm{SiH}_{2}$ and MeOH; Table S1. Effect of different hydrosilanes on the hydrogenation of HMF to BHMF.

Author Contributions: Data curation, J.L.; Investigation, J.L., W.Z. and Y.X.; Supervision, S.Y.; Conceptualization, H.L.; Funding acquisition, S.Y.; Project administration, S.Y.; Writing-original draft, J.L.; Writing-review and editing, H.L. and S.Y.

Funding: The work was financially supported by the Key Technologies R\&D Program of China (2014BAD23B01), National Natural Science Foundation of China (21576059, 21666008), Fok Ying-Tong Education Foundation (161030), and Guizhou Science \& Technology Foundation ([2018]1037, [2017]5788).

Conflicts of Interest: There are no conflicts to declare.

\section{References}

1. Li, H.; Fang, Z.; Luo, J.; Yang, S. Direct conversion of biomass components to the biofuel methyl levulinate catalyzed by acid-based bifunctional zirconia-zeolites. Appl. Catal. B. Environ. 2017, 200, 182-191. [CrossRef]

2. Hu, L.; Xu, J.; Zhou, S.; He, A.; Tang, X.; Lin, L.; Zhao, Y. Catalytic advances in the production and application of biomass-derived 2,5-dihydroxymethylfuran. ACS Catal. 2018, 8, 2959-2980. [CrossRef]

3. Patel, M.; Kumar, A. Production of renewable diesel through the hydroprocessing of lignocellulosic biomass-derived bio-oil: A review. Renew. Sustain. Energy Rev. 2016, 58, 1293-1307. [CrossRef] 
4. Qin, Y.; Yu, L.; Wu, R.; Yang, D.; Qiu, X.; Zhu, J.Y. Biorefinery lignosulfonates from sulfite-pretreated softwoods as dispersant for graphite. ACS Sustain. Chem. Eng. 2016, 4, 2200-2205. [CrossRef]

5. Li, H.; Fang, Z.; Smith Jr, R.L.; Yang, S. Efficient valorization of biomass to biofuels with bifunctional solid catalytic materials. Proc. Energy Combust. 2016, 55, 98-194. [CrossRef]

6. Li, H.; Riisager, A.; Saravanamurugan, S.; Pandey, A.; Sangwan, R.S.; Yang, S.; Luque, R. Carbon-increasing catalytic strategies for upgrading biomass into energy-intensive fuels and chemicals. ACS Catal. 2017, 8, 148-187. [CrossRef]

7. Román-Leshkov, Y.; Chheda, J.N.; Dumesic, J.A. Phase modifiers promote efficient production of hydroxymethylfurfural from fructose. Science 2006, 312, 1933-1937. [CrossRef] [PubMed]

8. Qi, X.; Watanabe, M.; Aida, T.M.; Smith, R.L., Jr. Efficient process for conversion of fructose to 5hydroxymethylfurfural with ionic liquids. Green Chem. 2009, 11, 1327-1331. [CrossRef]

9. Chen, J.; Li, K.; Chen, L.; Liu, R.; Huang, X.; Ye, D. Conversion of fructose into 5-hydroxymethylfurfural catalyzed by recyclable sulfonic acid-functionalized metal-organic frameworks. Green Chem. 2014, 16, 2490-2499. [CrossRef]

10. Zhao, H.; Holladay, J.E.; Brown, H.; Zhang, Z.C. Metal chlorides in ionic liquid solvents convert sugars to 5-hydroxymethylfurfural. Science 2007, 316, 1597-1600. [CrossRef] [PubMed]

11. Hu, S.; Zhang, Z.; Song, J.; Zhou, Y.; Han, B. Efficient conversion of glucose into 5-hydroxymethylfurfural catalyzed by a common Lewis acid $\mathrm{SnCl}_{4}$ in an ionic liquid. Green Chem. 2009, 11, 1746-1749. [CrossRef]

12. Choudhary, V.; Mushrif, S.H.; Ho, C.; Anderko, A.; Nikolakis, V.; Marinkovic, N.S.; Vlachos, D.G. Insights into the interplay of Lewis and Brønsted acid catalysts in glucose and fructose conversion to 5-(hydroxymethyl) furfural and levulinic acid in aqueous media. J. Am. Chem. Soc. 2013, 135, 3997-4006. [CrossRef] [PubMed]

13. Teong, S.P.; Yi, G.; Zhang, Y. Hydroxymethylfurfural production from bioresources: Past, present and future. Green Chem. 2014, 16, 2015-2026. [CrossRef]

14. Rout, P.K.; Nannaware, A.D.; Prakash, O.; Kalra, A.; Rajasekharan, R. Synthesis of hydroxymethylfurfural from cellulose using green processes: A promising biochemical and biofuel feedstock. Chem. Eng. Sci. 2016, 142, 318-346. [CrossRef]

15. Zhang, J.; Li, J.; Tang, Y.; Lin, L.; Long, M. Advances in catalytic production of bio-based polyester monomer 2,5-furandicarboxylic acid derived from lignocellulosic biomass. Carbohyd. Polym. 2015, 130, 420-428. [CrossRef] [PubMed]

16. van Putten, R.J.; Van Der Waal, J.C.; De Jong, E.D.; Rasrendra, C.B.; Heeres, H.J.; de Vries, J.G. Hydroxymethylfurfural, a versatile platform chemical made from renewable resources. Chem. Rev. 2013, 113, 1499-1597. [CrossRef] [PubMed]

17. Hu, L.; Lin, L.; Liu, S. Chemoselective hydrogenation of biomass-derived 5-hydroxymethylfurfural into the liquid biofuel 2,5-dimethylfuran. Ind. Eng. Chem. Res. 2014, 53, 9969-9978. [CrossRef]

18. Román-Leshkov, Y.; Barrett, C.J.; Liu, Z.Y.; Dumesic, J.A. Production of dimethylfuran for liquid fuels from biomass-derived carbohydrates. Nature 2007, 447, 982-985. [CrossRef] [PubMed]

19. Audemar, M.; Vigier, K.D.O.; Clacens, J.M.; De Campo, F.; Jérôme, F. Combination of $\mathrm{Pd} / \mathrm{C}$ and Amberlyst-15 in a single reactor for the acid/hydrogenating catalytic conversion of carbohydrates to 5-hydroxy-2,5-hexanedione. Green Chem. 2014, 16, 4110-4114. [CrossRef]

20. Wang, T.; Zhang, J.; Xie, W.; Tang, Y.; Guo, D.; Ni, Y. Catalytic transfer hydrogenation of biobased HMF to 2,5-bis-(hydroxymethyl) furan over $\mathrm{Ru} / \mathrm{Co}_{3} \mathrm{O}_{4}$. Catalysts 2017, 7, 92. [CrossRef]

21. Revunova, K.; Nikonov, G.I. Main group catalysed reduction of unsaturated bonds. Dalton Trans. 2015, 44, 840-866. [CrossRef] [PubMed]

22. Kwon, Y.; de Jong, E.; Raoufmoghaddam, S.; Koper, M.T. Electrocatalytic hydrogenation of 5hydroxymethylfurfural in the absence and presence of glucose. ChemSusChem 2013, 6, 1659-1667. [CrossRef] [PubMed]

23. Alamillo, R.; Tucker, M.; Chia, M.; Pagán-Torres, Y.; Dumesic, J. The selective hydrogenation of biomassderived 5-hydroxymethylfurfural using heterogeneous catalysts. Green Chem. 2012, 14, 1413-1419. [CrossRef]

24. Chen, B.; Li, F.; Huang, Z.; Yuan, G. Carbon-coated Cu-Co bimetallic nanoparticles as selective and recyclable catalysts for production of biofuel 2,5-dimethylfuran. Appl. Catal. B-Environ. 2017, 200, 192-199. [CrossRef]

25. Aellig, C.; Jenny, F.; Scholz, D.; Wolf, P.; Giovinazzo, I.; Kollhoff, F.; Hermans, I. Combined 1,4-butanediol lactonization and transfer hydrogenation/hydrogenolysis of furfural-derivatives under continuous flow conditions. Catal. Sci. Technol. 2014, 4, 2326-2331. [CrossRef] 
26. Upare, P.P.; Hwang, Y.K.; Hwang, D.W. An integrated process for the production of 2,5dihydroxymethylfuran and its polymer from fructose. Green Chem. 2018, 20, 879-885. [CrossRef]

27. Li, Q.; Man, P.; Yuan, L.; Zhang, P.; Li, Y.; Ai, S. Ruthenium supported on CoFe layered double oxide for selective hydrogenation of 5-hydroxymethylfurfural. Mol. Catal. 2017, 431, 32-38. [CrossRef]

28. Shen, R.; Zhang, M.; Xiao, J.; Dong, C.; Han, L.B. Ph ${ }_{3}$ P-Mediated Highly Selective C( $\alpha$ )-P Couplings of Quinone Monoacetals with $\mathrm{R}_{2} \mathrm{P}(\mathrm{O}) \mathrm{H}$ : Convenient and Practical Synthesis of ortho-Phosphinyl Phenols. Green Chem. 2018, 20, 5111-5116. [CrossRef]

29. Hao, W.; Li, W.; Tang, X.; Zeng, X.; Sun, Y.; Liu, S.; Lin, L. Catalytic transfer hydrogenation of biomass-derived 5-hydroxymethyl furfural to the building block 2,5-bishydroxymethyl furan. Green Chem. 2016, 18, 1080-1088. [CrossRef]

30. Wei, J.; Cao, X.; Wang, T.; Liu, H.; Tang, X.; Zeng, X.; Lin, L. Catalytic transfer hydrogenation of biomassderived 5-hydroxymethylfurfural into 2,5-bis (hydroxymethyl) furan over tunable Zr-based bimetallic catalysts. Catal. Sci. Technol. 2018, 8, 4474-4484. [CrossRef]

31. Thananatthanachon, T.; Rauchfuss, T.B. Efficient route to hydroxymethylfurans from sugars via transfer hydrogenation. ChemSusChem 2010, 3, 1139-1141. [CrossRef] [PubMed]

32. Thananatthanachon, T.; Rauchfuss, T.B. Efficient production of the liquid fuel 2,5-dimethylfuran from fructose using formic acid as a reagent. Angew. Chem. 2010, 122, 6766-6768. [CrossRef]

33. Wu, W.; Zhao, W.; Fang, C.; Wang, Z.; Yang, T.; Li, H.; Yang, S. Quantitative hydrogenation of furfural to furfuryl alcohol with recyclable KF and hydrosilane at room temperature in minutes. Catal. Commun. 2018, 105, 6-10. [CrossRef]

34. Roy, A.K. A review of recent progress in catalyzed homogeneous hydrosilation (hydrosilylation). Adv. Organomet. Chem. 2007, 55. [CrossRef]

35. Oestreich, M.; Hermeke, J.; Mohr, J. A unified survey of Si-H and H-H bond activation catalysed by electron-deficient boranes. Chem. Soc. Rev. 2015, 44, 2202-2220. [CrossRef] [PubMed]

36. Muthukumar, A.; Mamillapalli, N.C.; Sekar, G. Potassium phosphate-catalyzed chemoselective reduction of $\alpha$-keto amides: Route to synthesize passerini adducts and 3-phenyloxindoles. Adv. Synth. Catal. 2016, 358, 643-652. [CrossRef]

37. Xie, W.; Zhao, M.; Cui, C. Cesium carbonate-catalyzed reduction of amides with hydrosilanes. Organometallics 2013, 32, 7440-7444. [CrossRef]

38. Li, H.; Zhao, W.; Dai, W.; Long, J.; Watanabe, M.; Meier, S.; Saravanamurugan, S.; Yang, S.; Riisager, A. Noble metal-free upgrading of multi-unsaturated biomass derivatives at room temperature: Silyl species enable reactivity. Green Chem. 2018. [CrossRef]

39. Li, H.; Zhao, W.; Saravanamurugan, S.; Dai, W.; He, J.; Meier, S.; Yang, S.; Riisager, A. Control of selectivity in hydrosilane-promoted heterogeneous palladium-catalysed reduction of furfural and aromatic carboxides. Commun. Chem. 2018, 1, 32. [CrossRef]

40. Zhao, W.; Yang, T.; Li, H.; Wu, W.; Wang, Z.; Fang, C.; Saravanamurugan, S.; Yang, S. Highly recyclable fluoride for enhanced cascade hydrosilylation-cyclization of levulinates to $\gamma$-valerolactone at low temperatures. ACS Sustain. Chem. Eng. 2017, 5, 9640-9644. [CrossRef]

41. Ding, K.; Zannat, F.; Morris, J.C.; Brennessel, W.W.; Holland, P.L. Coordination of N-methylpyrrolidone to iron(II). J. Organomet. Chem. 2009, 694, 4204-4208. [CrossRef]

42. Bisz, E.; Szostak, M. 2-Methyltetrahydrofuran: A green solvent for iron-catalyzed cross-coupling reactions. ChemSusChem 2018, 11, 1290-1294. [CrossRef] [PubMed]

43. Yan, K.; Wu, G.; Lafleur, T.; Jarvis, C. Production, properties and catalytic hydrogenation of furfural to fuel additives and value-added chemicals. Renew. Sustain. Energy Rev. 2014, 38, 663-676. [CrossRef]

44. Sheldon, R.A. Fundamentals of green chemistry: Efficiency in reaction design. Chem. Soc. Rev. 2012, 41, 1437-1451. [CrossRef] [PubMed]

45. Byrne, F.P.; Jin, S.; Paggiola, G.; Petchey, T.H.M.; Clark, J.H.; Farmer, T.; Hunt, A.J.; McElroy, C.R.; Sherwood, J. Tools and techniques for solvent selection: Green solvent selection guides. Sustain. Chem. Process 2016, 4, 7. [CrossRef]

46. Alder, C.M.; Hayler, J.D.; Henderson, R.K.; Redman, A.M.; Shukla, L.; Shuster, L.E.; Sneddon, H.F. Updating and further expanding GSK's solvent sustainability guide. Green Chem. 2016, 18, 3879-3890. [CrossRef]

47. Kumar, G.; Muthukumar, M.A.; Sekar, G. A Mild and chemoselective hydrosilylation of $\alpha$-keto amides using $\mathrm{Cs}_{2} \mathrm{CO}_{3} / \mathrm{PMHS} / 2-\mathrm{MeTHF}$ System. J. Org. Chem. 2017, 33, 4883-4890. [CrossRef] 
48. Fulajtárova, K.; Soták, T.; Hronec, M.; Vávra, I.; Dobročka, E.; Omastová, M. Aqueous phase hydrogenation of furfural to furfuryl alcohol over Pd-Cu catalysts. Appl. Catal. A 2015, 502, 78-85. [CrossRef]

49. Li, H.; Smith, R.L. Solvents take control. Nat. Catal. 2018, 1, 176-177. [CrossRef]

50. Bornschein, C.; Werkmeister, S.; Junge, K.; Beller, M. TBAF-catalyzed hydrosilylation for the reduction of aromatic nitriles. New J. Chem. 2013, 37, 2061-2065. [CrossRef]

51. Zhao, W.; Wu, W.; Li, H.; Fang, C.; Yang, T.; Wang, Z.; Yang, S. Quantitative synthesis of 2,5-bis (hydroxymethyl)furan from biomass-derived 5-hydroxymethylfurfural and sugars over reusable solid catalysts at low temperatures. Fuel 2018, 217, 365-369. [CrossRef]

52. Kira, M.; Sato, K.; Sakurai, H. Reduction of carbonyl compounds with pentacoordinate hydridosilicates. J. Org. Chem. 1987, 52, 948-949. [CrossRef]

53. Ryoichi, K.; Masatoshi, T.; Yoshihiko, I. Reduction of amides to amines via catalytic hydrosilylation by a rhodium complex. Tetrahedron Lett. 1998, 39, 1017-1020. [CrossRef]

54. Rendler, S.; Oestreich, M. Hypervalent Silicon as a reactive site in selective bond-forming processes. Synthesis 2005, 17, 1727-1747. [CrossRef]

(C) 2018 by the authors. Licensee MDPI, Basel, Switzerland. This article is an open access article distributed under the terms and conditions of the Creative Commons Attribution (CC BY) license (http:/ / creativecommons.org/licenses/by/4.0/). 